\title{
O MODAL FERROVIÁRIO E A IMPORTÂNCIA DE REVITALIZAÇÃO DA MALHA PARA TRANSPORTE DE PASSAGEIROS: UMA REVISÃO DA LITERATURA
}

\author{
ISADORA DE PAULA BASTOS ${ }^{1}$
}

${ }^{1}$ Mestre em Engenharia Civil pela Universidade Federal Fluminense- isadora.bastos@engenharia.ufjf.br

\section{RESUMO}

O transporte ferroviário brasileiro viveu, durante muitos anos, grande descaso por conta do crescimento do transporte rodoviário e pela falta de investimentos na modernização de sua malha. Contudo, após o processo de concessões ocorrido no início da década de 90, o transporte ferroviário passou a viver uma nova realidade, com um maior investimento, já que as empresas que foram desestatizadas melhoraram seus indicadores e conseguiram se tornar mais competitivas no mercado. Atualmente, dentro desse contexto, a maior parte da malha ferroviária brasileira é usada para o transporte de cargas e um volume muito pequeno para o transporte de passageiros, normalmente aproveitado para o turismo. Porém, se algumas das linhas fossem revitalizadas para o tráfego de pessoas, conseguiríamos minimizar os congestionamentos, os impactos ambientais, o tempo de viagem, oferecer maior conforto, segurança, oferecendo com isso grande incentivo ao transporte público. O presente estudo traz uma pesquisa teórica sobre o assunto, espera-se que auxilie outras pesquisas sobre o assunto.

Palavras-chave: Ferrovias; Revitalização; Transporte.

\section{RAILWAY MODAL AND THE IMPORTANCE OF REVITALIZATION FOR PASSENGER TRANSPORT: A LITERATURE REVIEW}

\begin{abstract}
For many years, Brazilian rail transport had been largely neglected by the growth of road transport and by the lack of investments in the modernization of its network. However, after the concessions process, which took place in the early 1990s, rail transport started to live a new reality, with greater investment, as companies that were privatized improved their indicators and were able to become more competitive in the market. Currently, within this context, most of the rail network was used for the transport of cargoes and a very small volume for the transport of passengers, usually used for tourism. However, if some of the lines were revitalized for people traffic, we would be able to minimize congestion, environmental impacts, travel time, offer greater comfort and safety, thus offering a great incentive to public transportation. The present
\end{abstract}


study provides a theoretical research on the subject. The results are expected will aid further research on the subject.

Keywords: Railways; Revitalization; Transport

\section{INTRODUÇÃO}

Quando se discute quais são os elementos de maior importância para o desenvolvimento de países e regiões, devemos necessariamente considerar a importância de se ter um sistema de transporte eficiente. $\mathrm{O}$ modal ferroviário, em função de suas características que lhe proporcionam grande eficiência, consagrou-se como um veículo de transformação econômica, assumindo um importante papel estratégico na composição da matriz de transporte (CNT - CONFEDERAÇÃO NACIONAL DOS TRANSPORTES, 2013).

Dentro desse contexto, o transporte ferroviário se voltou apenas para $\mathrm{o}$ transporte de cargas, excetuando os casos de transporte urbano de grandes metrópoles e de casos isolados. Desde o final da década de 90, muito se fala em revitalizar e modernizar o transporte ferroviário para o transporte de passageiros. Vários programas do governo já foram lançados com esse objetivo; mas, apesar disso, pouco foi realmente feito, talvez devido ao pouco investimento na área e a falta de um planejamento eficaz (CNT - CONFEDERAÇÃO NACIONAL DOS TRANSPORTES, 2013).

A desativação da modalidade de transporte de passageiros por vias férreas foi bastante prejudicial para as cidades onde passam ferrovias, pois esse transporte atendia às finalidades turísticas, sociais, culturais, econômicas e de desenvolvimento regional (CNT - CONFEDERAÇÃO NACIONAL DOS TRANSPORTES, 2013).

O presente trabalho tem como principais objetivos descrever um breve histórico sobre as ferrovias no Brasil e no mundo; expor as vantagens do modal ferroviário em relação ao modal rodoviário; além de apontar as deficiências dos transportes públicos no Brasil.

\section{REVISÃO DA LITERATURA}




\subsection{O Surgimentos das Primeiras Locomotivas e das Linhas Férreas}

De acordo com o Banco Nacional de Desenvolvimento Econômico e Social (BNDES, 1998), a história do transporte ferroviário, em escala comercial, principia no século XIX e foi marcada por fatos relevantes, tais como: em 1825, com a primeira viagem por $25 \mathrm{~km}$, em caráter inaugural, entre Stockton e Darlington, interior da Inglaterra e, em 1836, quando foi inaugurada a primeira linha de trem suburbana do mundo, ligando London Bridge ao subúrbio londrino de Greenwich.

Assim, iniciava-se o grande ciclo ferroviário que atingiria os rincões mais longínquos nos mais diversos países, revolucionando os transportes e a própria estrutura socioeconômica, em escala mundial (BNDES, 1998).

\subsection{A Malha Ferroviária no Brasil}

De acordo com a CNT (2013), as primeiras ferrovias que surgiram no Brasil foram durante o ciclo do café, que predominou da segunda metade do século XIX até meados de 1930. Nessa época, a economia do país era primordialmente agrícola e agroexportadora.

Para o BNDES (1998), um fator comum de destaque emergia do quadro ferroviário mundial àquela época: as primeiras linhas eram destinadas ao transporte de passageiros, a curtas distâncias, configurando-se assim o transporte regional ou de vizinhança.

Dada a baixa atratividade dos empreendimentos para a construção ferrovias, o governo imperial brasileiro instituiu, em 1852, a Lei de Garantia de Juros (decreto $\mathrm{n}^{\circ}$ 64), que autorizava a concessão da construção e exploração de ferrovias pelo prazo máximo de 90 anos. Esta lei proibia a construção de outra ferrovia num raio de cinco léguas (cerca de 33,0 km), o que conferia ao administrador privado o monopólio do transporte ferroviário dentro da região (CNT, 2013).

O CNT (2013), aponta ainda que, dessa forma, houve um crescimento desordenado e sem planejamento da malha, resultando, como exemplo, na utilização de diferentes tipos de bitolas nos diversos trechos, o que tornava inviável sua integração. 
Além disso, os mecanismos criados pela Lei de Garantia de Juros passaram a ser insustentáveis para o Tesouro Nacional.

Segundo Lang (2007), isso trouxe como resultado benefícios da lei que foram reduzidos, o que afastou a iniciativa privada desses empreendimentos.

Para a CNT (2013), a partir da década de 1920, já na República, a construção de rodovias pavimentadas foi ampliada, passando a competir com as ferrovias por recursos públicos e pelo transporte de cargas e passageiros. Isso representou perda de receita para o modal ferroviário e menos investimentos em infraestrutura para o setor; apesar dessas dificuldades, desde 1920 até 1950, a malha ferroviária nacional se expandiu em mais de $8.000 \mathrm{~km}$. Contribuiu para esse processo não apenas as vantagens naturais das ferrovias no transporte terrestre, mas também pelo desenvolvimento, ao longo do tempo, de novas tecnologias que permitiram a substituição de trens movidos a vapor por veículos de tração elétrica e, mais para frente, por motores a diesel.

O transporte ferroviário de passageiros de curta e de longa distância evoluiu continuamente em concomitância com o transporte de carga, até se confrontar com a acirrada competição do transporte rodoviário, em particular a partir da década de 50 e, mais recentemente, com o transporte aéreo (BNDES, 1998).

Conforme citou Castro (2000), em 1957, foi criada uma empresa estatal a Rede Ferroviária Federal S/A (RFFSA) com o objetivo de integrar, sob uma mesma administração, a rede ferroviária pertencente à União. A criação da empresa trouxe avanços para o setor, como o crescimento da tonelagem transportada e o aumento da produtividade do trabalho. Apesar do desenvolvimento das ferrovias até então, elas ainda representavam $90 \%$ do déficit orçamentário público na metade do século.

A grande interferência da administração pública no setor ferroviário, no Brasil e em outros países, iria, a partir da década de 1970, dar sinais de que os altos custos e o baixo nível de eficiência, que estavam tornando proibitiva a existência das ferrovias, poderiam estar associados ao modelo de operação vigente (CNT, 2013).

Na década de 1980, com a crise fiscal do Estado brasileiro, as receitas da RFFSA não eram suficientes para arcar com a dívida contraída. Na década de 1990, a malha da RFFSA foi concedida (CNT, 2013). Essa foi a primeira fase de desenvolvimento do sistema após a concessão, que se consubstanciou na recuperação da 
via permanente e do material rodante, bastante degradados pela falta de recursos de manutenção da capacidade instalada entre 1993 e 1996 (BNDES, 2006).

\subsection{A importância das ferrovias no desenvolvimento dos países}

De acordo com Barros (2013), a percepção das ferrovias como indutoras do crescimento pela redução do custo de transporte esteve presente em diversos trabalhos realizados no exterior, sendo dois de maior destaque. $O$ primeiro estima que, na ausência da infraestrutura ferroviária, o PIB dos Estados Unidos teria um valor de 10\% a $20 \%$ inferior ao apresentado no final da década de 60 . No segundo estudo, anterior ao citado, realizado no Japão, verificou-se também uma forte contribuição da provisão da infraestrutura ferroviária para o crescimento do PIB daquele País no período de 1875 até 1940.

Rostow (1961), em seu trabalho sobre os estágios de desenvolvimento econômico, atribuiu às ferrovias o papel de catalisador da transformação econômica vivenciada pelo Ocidente desde meados do século XIX. A Revolução Industrial desencadeou profundas mudanças estruturais que demandaram, mais do que em qualquer outro momento da história, a capacidade de se transportar um grande volume de passageiros e cargas. Essas alterações na estrutura econômica permitiram o desenvolvimento do transporte ferroviário em diversos países, que se manteve como o mais importante meio de transporte terrestre até a década de 1930.

Até a década de 1980, os sistemas ferroviários nos diferentes países estavam centralizados em empresas públicas de poder nacional. Isso garantia que os sistemas lucrassem com os ganhos de escala, fornecessem serviços voltados para o interesse da sociedade e impedia possíveis abusos que um monopolista privado poderia incorrer sobre os usuários. Porém, devido aos crescentes custos e ineficiência do setor, iriam pressionar por reformas na estrutura regulatória. As experiências na desregulamentação pública do setor foram variadas, sendo algumas de sucesso como no caso da Alemanha, Estados Unidos e Japão, e outras que acabaram por apresentar resultados inferiores, como no caso do Reino Unido (CNT, 2013).

Segundo o BNDES (1998), qualquer que seja a estratégia de recuperação do papel de ferrovia nos transportes em geral, o elemento chave tem sido, 
majoritariamente, a introdução de forças do mercado, isto é, o princípio da lucratividade na operação ferroviária, ou então, o de que a operação demande o menor nível possível de subsídio.

\subsection{As concessões ferroviárias brasileiras: evolução e desempenho do setor ferroviário brasileiro}

A possibilidade de participação da iniciativa privada na oferta de serviços públicos - como o de transporte ferroviário de cargas - associado à exploração da infraestrutura, por concessão, está prevista nos artigos 21 e 175 da Constituição Federal de 1988. Apesar da previsão constitucional, a retomada da participação do setor privado no modal ferroviário só foi efetivada com a inclusão da RFFSA no Plano Nacional de Desestatização (PND), em 1992 (decreto $n^{\circ}$ 473/92). O processo de concessão da malha ferroviária foi realizado com base na lei $\mathrm{n}^{\circ}$ 8.987/95 (BNDES, 2006).

A estrutura organizacional escolhida pelo governo federal para a realização das concessões no Brasil foi a separação vertical, ou seja, a empresa responsável pela concessão controla a infraestrutura, a operação e a comercialização dos serviços de transporte ferroviário em uma determinada região. No Brasil, os lotes concessionados de ferrovias foram segmentados conforme as superintendências da RFFSA (RESENDE; OLIVEIRA; SOUSA, 2009).

As licitações ocorreram entre 1996 e 1998 e utilizaram como critério o maior valor de outorga. O preço mínimo, para cada malha, foi determinado considerando o pagamento da concessão, do arrendamento e da venda de bens de pequeno valor. Foram leiloadas sete malhas sendo a maior delas a Centro-Leste com $7.080 \mathrm{~km}$ (CNT, 2013).

A concessão ferroviária compreende em 12 trechos distintos que totalizam em $28.692 \mathrm{~km}$, ou seja, 94\% da malha existente, com cada linha operada por uma empresa individual. $\mathrm{O}$ restante compreende em linhas locais, trens urbanos e turísticos somando $1.437 \mathrm{~km}(\mathrm{CNT}, 2013)$.

As concessões ferroviárias trouxeram diversos ganhos para a estrutura logística e econômica nacional. Os mais imediatos decorreram do recolhimento de mais de $\mathrm{R} \$ 1,76$ bilhão pela União com os leilões na década de 1990, seguido pela desoneração dos cofres públicos dos déficits que o setor apresentava. Após o período inicial de transição, 
a maior parte das ferrovias observou um resultado positivo do patrimônio líquido, após décadas de fechamentos negativos da RFFSA (CNT, 2013).

O BNDES (2006) aponta ainda que, após o período de concessão do Sistema Ferroviário, ocorrido entre 1996 e 1999, a malha ferroviária da Rede passou a ter uma nova configuração, conforme Tabela 1 .

Tabela 1 - Concessionárias RFFSA

\section{Concessionárias RFFSA - Dados Básicos}

\begin{tabular}{|c|c|c|c|c|c|c|}
\hline \multirow[t]{2}{*}{ Concessionária } & \multirow[t]{2}{*}{ Malha } & \multirow[t]{2}{*}{ Bitola } & \multirow{2}{*}{$\begin{array}{c}\text { Extensão } \\
\left.\qquad \begin{array}{c}(1.000 \\
\mathrm{km}\end{array}\right)\end{array}$} & \multicolumn{2}{|c|}{$\begin{array}{c}\text { Carregamento } 2005 \\
\text { (Milhão) }\end{array}$} & \multirow{2}{*}{$\begin{array}{c}\text { Contrato } \\
\text { R\$ } \\
\text { Milhões }\end{array}$} \\
\hline & & & & $T K U^{1}$ & $T U^{2}$ & \\
\hline Ferrovia Novoeste S.A. & Oeste & métrica & 1,9 & 1,3 & 3,5 & 103,00 \\
\hline $\begin{array}{l}\text { Ferrovia } \\
\text { Centro-Atlântica S.A. }\end{array}$ & $\begin{array}{l}\text { Centro- } \\
\text { Leste }\end{array}$ & métrica & 8,1 & 10,7 & 27,6 & 511,60 \\
\hline MRS Logística S.A. & Sudeste & larga & 1,7 & 44,4 & 108,1 & $1.433,10$ \\
\hline $\begin{array}{l}\text { Ferrovia Tereza } \\
\text { Cristina S.A. }\end{array}$ & Tereza C. & métrica & 0,2 & 0,2 & 2,4 & 29,70 \\
\hline $\begin{array}{l}\text { América Latina } \\
\text { Logística }\end{array}$ & Sul & métrica & 7,2 & 15,4 & 21,7 & 344,40 \\
\hline $\begin{array}{l}\text { Companhia Ferroviária } \\
\text { do Nordeste }\end{array}$ & Nordeste & métrica & 4,2 & 0,8 & 1,4 & 23,90 \\
\hline $\begin{array}{l}\text { Ferrovias Bandeirantes } \\
\text { S.A. }\end{array}$ & & larga & 2,0 & 2,3 & 4,4 & 359,90 \\
\hline Ferroeste & & métrica & 0,2 & 0,3 & 1,5 & 40,70 \\
\hline Total & & & 25,6 & & & $2.846,30$ \\
\hline
\end{tabular}

${ }^{1}$ TKU: tonelada quilômetro útil.

${ }^{2} T U:$ tonelada útil.

Fonte: BNDES (2006).

A partir de 2000, o sistema ferroviário concedido ingressou numa segunda fase de investimentos, caracterizada pelo aumento da capacidade (aumento da oferta) e a expansão dos serviços logísticos. Nesse período, ampliaram-se os pátios de manobras, aumentou-se a capacidade de suporte da via permanente, construíram-se terminais de integração rodoferroviários e adquiriu-se novo material rodante (BNDES, 2006).

\subsection{A atual situação da estrutura e desempenho do setor ferroviário brasileiro}


De acordo com a Agência Nacional de Transportes Ferroviários (ANTF, 2015), a infraestrutura de transporte está no caminho crítico para que o Brasil alcance o desenvolvimento. Os resultados positivos da agroindústria, por exemplo, só serão alcançados se houver condições para escoamento da produção com eficiência, confiabilidade e custos compatíveis.

Não há no mundo qualquer outro país de dimensões continentais que tenha deixado de investir pesadamente no setor ferroviário. A matriz de transportes em nosso país apresenta grave distorção: passa pelas rodovias 58\% de tudo o que é transportado no Brasil, enquanto as ferrovias transportam apenas $25 \%$ do total e, as hidrovias, $13 \%$. Um país como o Brasil exigiria uma malha férrea de mais de 50 mil km (MINISTÉRIO DOS TRANSPORTES, 2010).

O Gráfico 1 demonstra a diferença entre o uso dos modais de transporte em alguns países.

Gráfico 1 - Matriz de transportes no mundo

\section{Matriz de transportes no mundo}

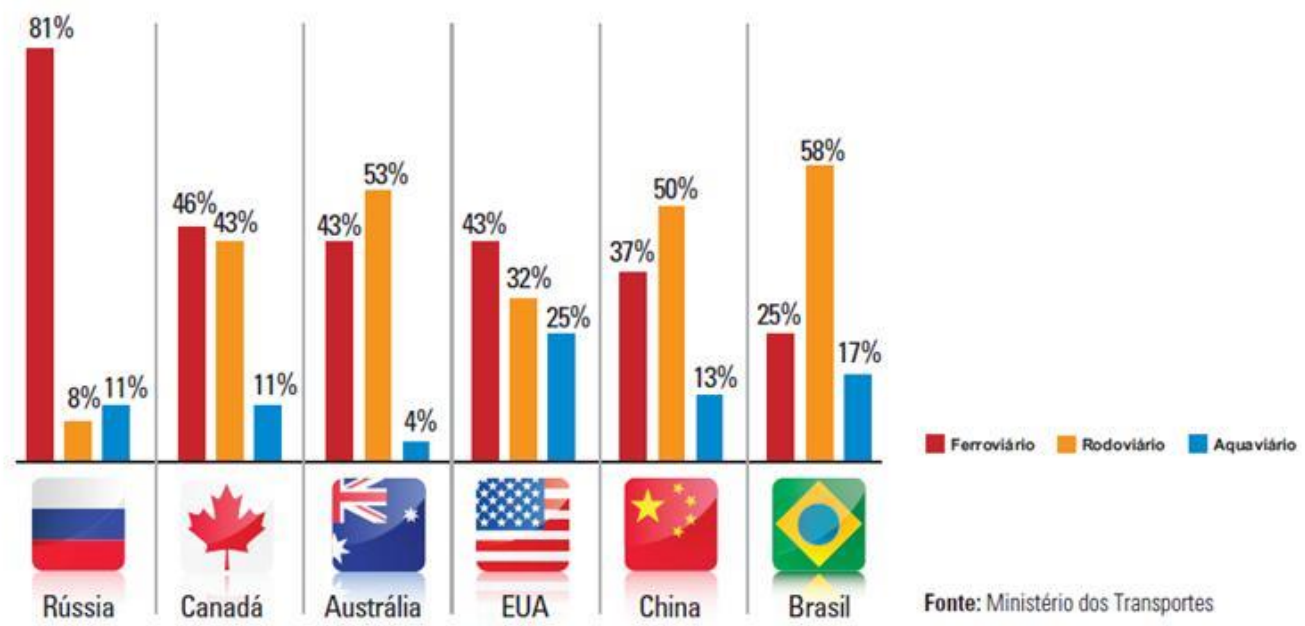

Fonte: Ministério dos Transportes (2010).

Observando o Gráfico 1, o transporte rodoviário do Brasil é o maior dentro os países citados, enquanto que o ferroviário é o menor. Fazendo uma comparação entre Brasil e Rússia, nota-se uma enorme discrepância entre esses modais: o Brasil utiliza do transporte rodoviário aproximadamente sete vezes mais que a Rússia; enquanto que o 
país russo tem $81 \%$ do seu transporte realizado por meio ferroviário e o Brasil apenas $25 \%$.

A dotação de recursos maiores para as rodovias em relação aos outros modais, nos programas do Governo Federal, não corresponde à meta de aumentar a participação das ferrovias na matriz de transportes, como observado na Tabela 2 (ANTF, 2015).

Tabela 2 - Alocação dos recursos nos principais planos de infraestrutura no Brasil Alocação dos recursos nos principais planos de infraestrutura no Brasil

\begin{tabular}{|c|c|c|c|}
\hline \multirow[b]{2}{*}{ Plano } & \multicolumn{3}{|c|}{ Participação (\%) } \\
\hline & Rodovias & Ferrovias & Outros \\
\hline PNLT $^{8}$ & $43 \%$ & $29 \%$ & $28 \%$ \\
\hline CNT $^{9}$ & $54 \%$ & $24 \%$ & $22 \%$ \\
\hline PAC $1(2007-2010)^{10}$ & $56 \%$ & $14 \%$ & $30 \%$ \\
\hline PAC $2(2011-2014)^{11}$ & $46 \%$ & $42 \%$ * & $12 \%$ \\
\hline
\end{tabular}

Fonte: Ministério dos Transportes (2010).

Para que o país continue crescendo, é necessário promover mudanças na matriz de transportes. A expansão e a recuperação do sistema ferroviário dependem fortemente de parcerias entre o setor privado (concessionárias e outras empresas ligadas ao setor) e o Governo Federal, proprietário da malha existente (ANTF, 2015).

Apesar de se investir mais em rodovias do que em ferrovias, segundo o Ministério dos Transportes (2010), o Gráfico 2 demonstra as previsões de aumento da malha ferroviária para 2025. 
Gráfico 2 - Previsão da matriz de transportes no Brasil para 2025

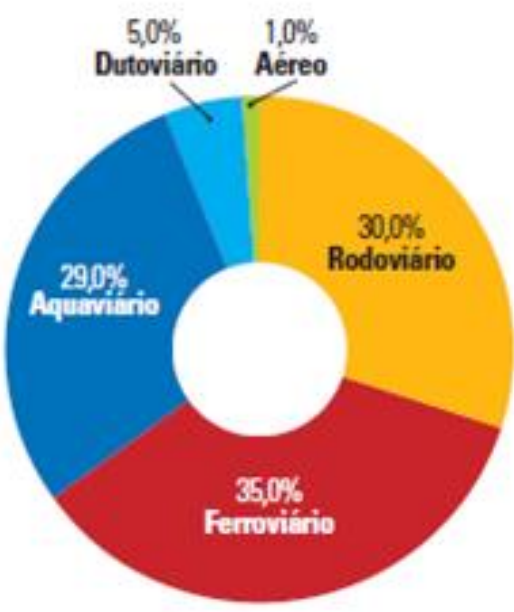

Fonte: Ministério dos Transportes (2010).

\subsection{Vantagens econômicas e ambientais do Transporte Ferroviário}

Segundo o Instituto de Pesquisa Econômica Aplicada (IPEA, 2010), o consumo de combustível por tonelada transportada em uma ferrovia moderna é de cerca de $40 \%$ do consumo em uma rodovia também moderna, como demonstra a Figura 1.

Figura 1 - Comparação do consumo de combustível para transportar 1 tonelada por $1000 \mathrm{~km}$ de via

\begin{tabular}{|c||c|c|}
\hline HIDROVIA & FERROVIA & RODOVIA \\
\hline 4 litros & 6 litros & 15 litros \\
\hline & &
\end{tabular}

Fonte: Departamento de Infraestrutura de Transportes (DNIT, 2006).

De acordo com a ANTF (2015), os trens de carga emitem 70\% menos dióxido de carbono $\left(\mathrm{CO}_{2}\right)$ e $66 \%$ menos monóxido de carbono $(\mathrm{CO})$ do que os caminhões que também transportam cargas, como demonstra a Figura 2. A emissão de gases carbono na atmosfera, em grandes quantidades, agravam o efeito estufa, prejudicando também o 
meio ambiente e a saúde das pessoas, pois essa emissão pode causar diversos problemas respiratórios além da poluição do ar.

Figura 2 - Matriz comparativa entre os modais de transporte quanto a emissão de poluentes na atmosfera

Matriz comparativa



$\mathrm{N}_{2} \mathrm{O} \quad \mathrm{NOx}$

Rodoviário $\quad 40,5$

Ferroviário $\quad 7,3$

Hidroviário $\quad 2,4$

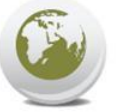

NOx $\quad \mathrm{CO}_{2}$

$65,2 \quad 1.625$

11,7

4,1

Bithros de
gramas
Oxido de

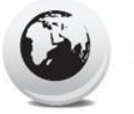

$\mathrm{CO}_{2} \quad \mathrm{CO}$

$480,4 \quad 2.549$

$324,6 \quad 915$

Milhơes de
quilos
Gás
Carbônico

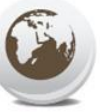

0

Milhares de
gramas
Monóxido
de Carbono

Fonte: ANTF (2015).

\subsection{Principais limitações do transporte ferroviário}

Segundo a ANTF (2015), as principais limitações do setor ferroviário, quando comparado aos outros modais de transporte, é que ela só se torna economicamente viável em grandes distâncias e para transportar grandes volumes, como demonstrado na Figura 3.

Pode-se observar que, para distâncias de até $400 \mathrm{~km}$, o transporte mais viável é o rodoviário, o ferroviário, pelo alto custo de sua infraestrutura se torna viável entre $400 \mathrm{~km}$ e $1500 \mathrm{~km}$, e o hidroviário entre $1500 \mathrm{~km}$ e $3000 \mathrm{~km}$.

Figura 3 - Vantagens comparativas por meio de transporte

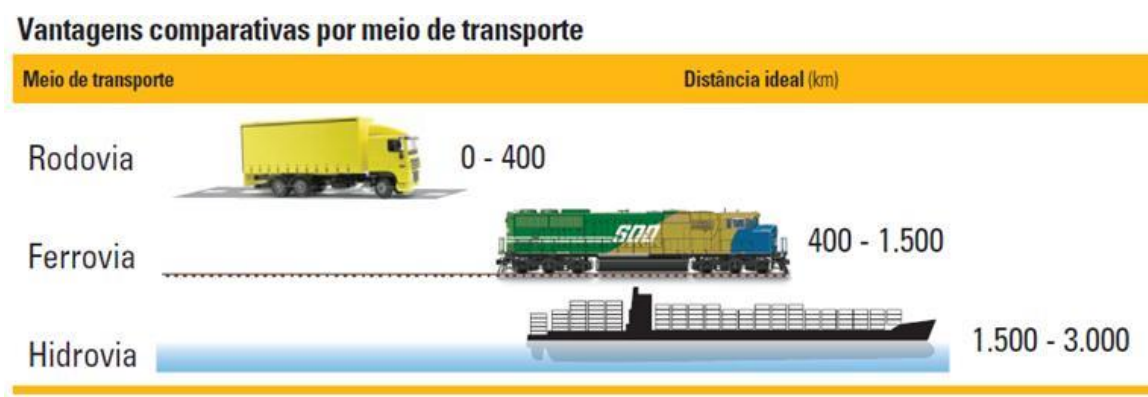

Fonte: Ministério dos Transportes (2010). 
Acrescenta ainda outro entrave que prejudicou muito a evolução deste meio, a existência de diferentes bitolas dificultando a interligação entre ferrovias (CNT, 2013). De acordo com a CNT (2000), a infraestrutura das ferrovias é bem mais cara do que a das rodovias e das hidrovias, essa comparação é demonstrada na Figura 4.

Figura 4 - Comparação do custo de $1 \mathrm{~km}$ da infraestrutura para os modais: hidrovia, ferrovia e rodovia

US\$ 34 mil

Fonte: DNIT (2006).

\subsection{O transporte de passageiros no Brasil}

A importância do transporte de passageiros para a eficiência econômica e mobilidade da população é condição de negócio, emprego, renda, cidadania e lucratividade. O serviço de transporte coletivo público é um serviço essencial para qualquer sociedade e sua economia. Garantir a eficaz movimentação de pessoas permitindo que alcancem seus destinos dentro de um padrão de qualidade deve ser o objetivo de qualquer sistema (CNT, 2002).

Segundo estudos do IPEA (2002), à medida que aumenta o tempo gasto no percurso casa-trabalho, tem-se uma perda da capacidade laborativa das pessoas. Até 40 minutos de viagem, ainda não se tem perda de produtividade a partir desse tempo, a perda cresce progressivamente. A partir de 80 minutos, ou seja, 1 hora e 20 minutos, a perda da produtividade já chega aos $21 \%$. A Tabela 3 apresenta uma relação entre o tempo de percurso até o trabalho versus redução na produtividade. 
Tabela 3 - Redução de produtividade devido ao tempo de viagem até o trabalho

\begin{tabular}{|c|c|}
\hline TEMPO DE VIAGEM & REDUÇÃO DE PRODUTIVIDADE \\
\hline 40 MINUTOS & NÄO CAUSAM \\
\hline 40 A 60 MINUTOS & $14 \%$ \\
\hline 60 A 80 MINUTOS & $16 \%$ \\
\hline$>80$ MINUTOS & $21 \%$ \\
\hline
\end{tabular}

Fonte: IPEA (2002).

A Figura 5 apresenta um fluxograma mostrando como a ineficiência do transporte público é prejudicial para a sociedade.

Figura 5 - Fluxograma de redução da eficiência dos transportes

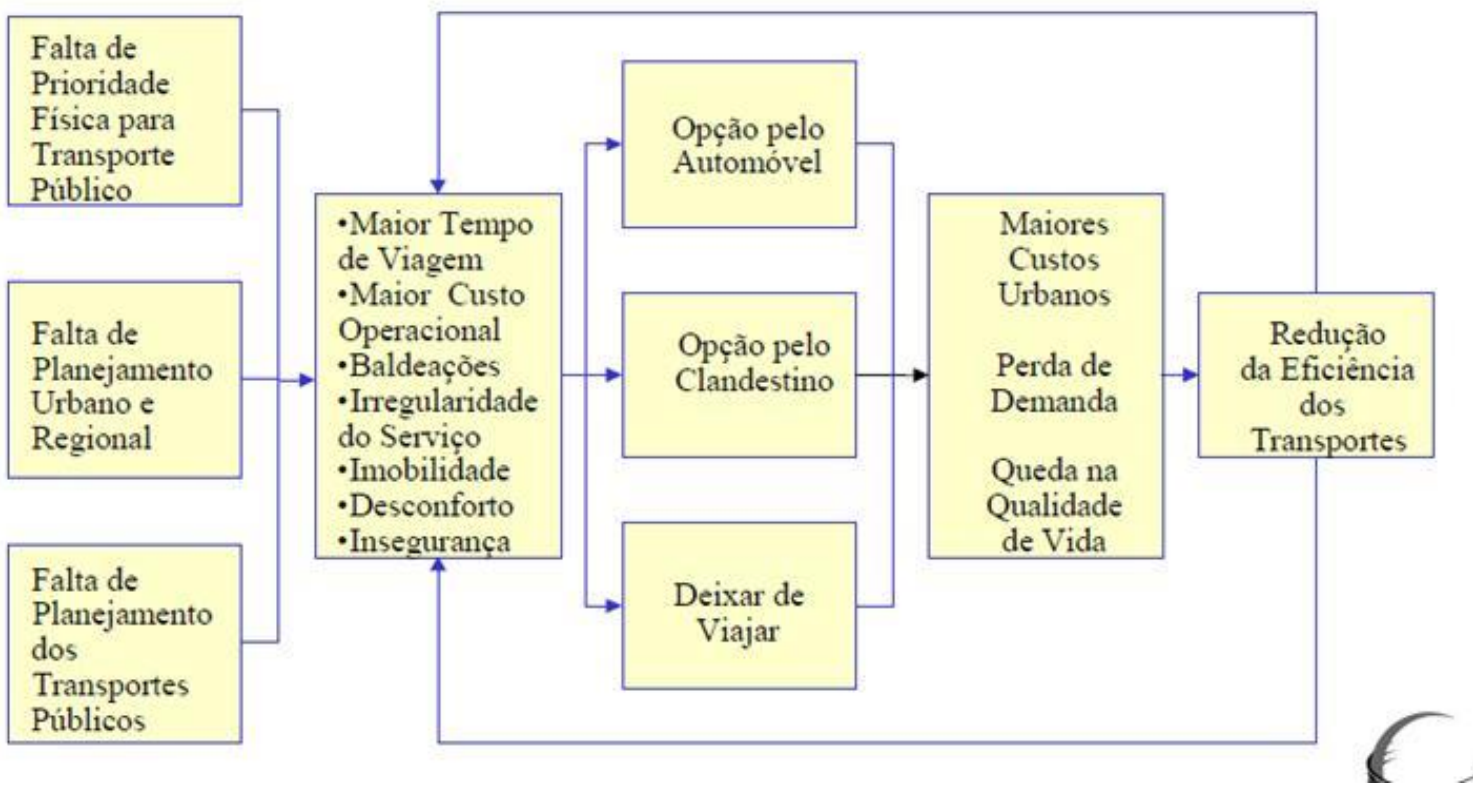

Fonte: CNT (2002).

\subsection{Plano de Revitalização das Ferrovias a partir da década de 90}

De acordo com o BNDES (1998) no final da década de 90, estavam em curso diversas experiências de reorganização de sistemas ferroviários nacionais, Europa Ocidental e Japão à frente. Qualquer que fosse a estratégia de recuperação do papel de ferrovia nos transportes em geral, o elemento chave foi, majoritariamente, a introdução de forças do mercado, isto é, o princípio da lucratividade na operação ferroviária, ou 
então, o de que a operação demande o menor nível possível de subsídio. No caso específico do transporte regional de passageiros, ou de cercanias, essa concepção negocial estimulou o desenvolvimento de novos veículos ferroviários, mais leves, modulares e apropriados para esse tipo de transporte.

No Brasil, para a seleção dos trechos que seriam revitalizados, foi feito um estudo que buscou identificar, dentre os mais promissores, aqueles que pudessem refletir as heterogeneidades existentes no Brasil, de natureza física, socioeconômica e de atratividade para a iniciativa privada (BNDES, 1998). Os trechos selecionados são os descritos na Figura 6.

Figura 6 - Trechos selecionados para a revitalização

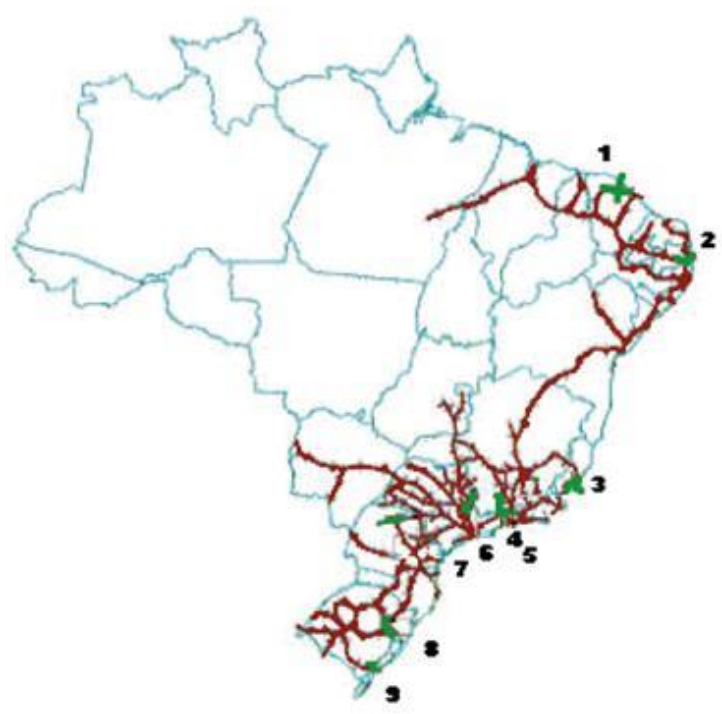

1 Fortaleza - Caucaia - São Luiz do Curu Itapipoca-Sobral

2 Campina Grande - Itabaiana - Pilar - Santa Rita Bayeux - João Pessoa - Cabedelo

3 Cachoeiro do Itapemirim - Viana - Vitória

Vargiruha - Três Coraçöes - Soledade de Minas Säo Lourenço - Itanhandu - Passa Quatro Cruzeiro

5 Itatiaia - Resende - Barra Mansa - Volta Redonda

Campinas - Paulínea - Moji Mirim - Moji Guaçu Aguai - São João da Boa Vista - Aguas da Prata - Poços de Caldas

7 Maringá - Mandaguari - Jandaia do Sul Apucarana - Rolândia - Cambé - Londrina

Caxias do Sul - Carlos Barbosa - Garibaldi . Bento Gonçalves - Farroupilha - Roca Sales Teutốnia - Montenegro - Porto Alegre

9 Pelotas - Rio Grande

Fonte: BNDES (1998).

Os nove trechos escolhidos perfazem $1.459 \mathrm{~km}$ de linhas férreas e abrigam em suas áreas de influência cerca de 9,4 milhões de pessoas residentes em 52 municípios (BNDES, 1998).

Parte-se da convicção de que a implantação de um sistema de transporte ferroviário de passageiros de cercanias funcionaria como corredor de transporte e como eixo de desenvolvimento. Como corredor de transporte, o trecho formaria o locus da tecnologia avançada e promoveria a integração física e operacional com os sistemas 
existentes de ônibus. Como eixo de desenvolvimento, ele seria a base para a criação de novos centros de comércio e serviços (BNDES, 1998).

Segundo a Agência Nacional de Transportes Terrestres (ANTT), em 2007, foi criado o Programa de Resgate do Transporte Ferroviário de Passageiros, que criaria as condições para o retorno do transporte de passageiros às ferrovias, promovendo o atendimento regional, social e turístico, onde viável, e a geração de emprego e renda. Os objetivos principais do programa são:

-Trem de turismo: geração de emprego e renda; desenvolvimento do turismo nas cidades servidas; preservação do patrimônio histórico ferroviário;

-Trens Regionais: promover a integração regional; desenvolver empreendimentos imobiliários e de serviços ao longo do trecho; minimizar a ociosidade de trechos ferroviários;

-Trens de alta velocidade e desempenho: promover a ligação por meio de trens de alta velocidade entre as cidades do Rio de Janeiro e São Paulo e entre Goiânia e Brasília.

\section{DISCUSSÃO}

Em comparação com outros países, o Brasil está muito atrás em termos de extensão da malha ferroviária, até mesmo comparando-o com países da América do Sul, como a Argentina. Enquanto o Brasil possui quase $30 \mathrm{mil} \mathrm{km} \mathrm{de} \mathrm{malha} \mathrm{ferroviária,} \mathrm{a}$ Argentina possui quase $37 \mathrm{mil} \mathrm{km}$ de ferrovias (INDEX MUNDI, 2019).

Apesar dos programas de revitalização de ferrovias terem sido planejados, para que eles possam ser executados, é necessária uma revitalização também das estações das áreas centrais das cidades envolvidas, além de serem construídas outras novas para que os passageiros estejam bem instalados e acomodados para o embarque e desembarque.

Esses programas de revitalização e expansão da malha nunca saíram do papel e, atualmente, com o cenário de crise, pouco se investe em infraestrutura ferroviária.

\section{CONCLUSÃO}


O objetivo deste estudo foi demonstrar o panorama do Sistema ferroviário brasileiro, com base no seu histórico e nos programas feitos para reestruturá-lo e revitalizá-lo.

A maior parte do modal ferroviário brasileiro é usado para o transporte de cargas, uma pequena parcela de sua extensão é utilizada para o transporte de passageiros. O transporte ferroviário se apresenta como uma alternativa sustentável e eficaz para os problemas de tráfego que assolam o país, mas sua infraestrutura cara pode ser um problema.

Apesar de alguns planejamentos já terem sido feitos para revitalizar o modal ferroviário de passageiros, pouca coisa saiu do papel. Talvez por falta de interesse da iniciativa privada ou de mais incentivo do governo, esse quadro não mude. Espera-se que, para trabalhos futuros, este artigo auxilie em um projeto de revitalização de um trecho de ferrovia para o transporte de passageiros.

\section{REFERÊNCIAS BIBLIOGRÁFICAS}

ANTF - Agência Nacional de Transportes Ferroviários. As Ferrovias e o Futuro do país. 2015.

ANTT - Agência Nacional de Transportes Terrestres. Programa de Resgate do Transporte Ferroviário de Passageiros. 2007. Disponível em:

<http://portal.antt.gov.br>. Acesso em 08 de março de 2016.

BARROS, J. M. F. M. - Avaliação dos Principais Métodos Analíticos de Cálculo de Capacidade de Tráfego Utilizados em Ferrovia Nacional e Internacional. Escola de Engenharia da UFMG, Belo Horizonte, 2013.

BNDES - Banco Nacional de Desenvolvimento Econômico e Social. Transporte Regional Ferroviário de Passageiros. Área de Projetos de Infraestrutura. Março, 1998.

BNDES - Banco Nacional de Desenvolvimento Econômico e Social.

Dimensionamento do Potencial de Investimentos do setor Ferroviário. 2006.

CASTRO, N. Privatização do Setor de Transportes no Brasil. BNDES, 2000.

CNT - Confederação Nacional do Transporte. Multimodalidade e as Hidrovias no Brasil. 2000.

CNT-Confederação Nacional de Transportes. Transporte de Passageiros. 2002. 
CNT - Confederação Nacional do Transporte. O Sistema Ferroviário Brasileiro. Transporte e Economia, 2013.

DNIT - Departamento Nacional de Infraestrutura e Transportes. Negócio nos trilhos. ENCONTREM, 2006.

INDEX MUNDI. Disponível em: <https://www.indexmundi.com/map/?v=113\&l=pt>. Acesso em 20 de agosto de 2019.

IPEA - Instituto de Pesquisa Econômica Aplicada. 2010. Disponível em: <http://www.ipea.gov.br/portal/>. Acesso em 09 de março de 2016.

LANG, A. E. As Ferrovias no Brasil e Avaliação Econômica de Projetos: uma Aplicação em Projetos Ferroviários. Dissertação apresentada para obtenção de título de Mestre. UnB, Brasília, 2007.

Ministério dos Transportes. Matriz de Transportes: presente e futuro. In: II Encontro de Ferrovias de Vitória, 2010.

RESENDE, P. T.; OLIVEIRA, M. P. V.; SOUSA, P. R. Análise do Modelo de Concessão no Transporte Ferroviário Brasileiro: a Visão dos Usuários. Revista do Mestrado em Administração e Desenvolvimento Empresarial da Universidade Estácio de Sá. Rio de Janeiro, 2009.

ROSTOW, W. W. The Stages of Economic Growth. Cambridge: Cambridge University Press, 1960. 